\title{
Hypertension treatment status and ultrasonic cardiography findings in temporary housing residents after the Kumamoto earthquake: a cross-sectional study
}

\author{
Hidenori Onishi', Osamu Yamamura ${ }^{2}$, Hiromasa Tsubouchi', Takeshi Hirobe ${ }^{4}$, Souichi Enomoto ${ }^{5}$, \\ Tami Yamamoto ${ }^{6}$, Satoshi Daitoku ${ }^{7}$, Yasutaka Mizukami ${ }^{8}$, Takahiro Kishimoto ${ }^{9}$, Yutaka Kai ${ }^{10}$, \\ Youichirou Hashimoto" ${ }^{11}$, Tadanori Hamano ${ }^{12}$, Bunji Kaku ${ }^{13}$, Hidekazu Terasawa ${ }^{14}$ \\ ${ }^{1}$ Department of Community Medicine, Faculty of Medical Science, University of Fukui, Yoshida-gun, Fukui, Japan \\ ${ }^{2}$ Department of Community Medicine, Faculty of Medical Science, University of Fukui and Second Department of Internal Medicine, \\ Faculty of Medical Science, University of Fukui, Yoshida-gun, Fukui, Japan \\ ${ }^{3}$ Department of Radiotechnology, Fukui-Ken Saiseikai Hospital, Fukui-city, Fukui, Japan \\ ${ }^{4}$ Department of Clinical Laboratory, Fukui Prefectural Hospital, Fukui-city, Fukui, Japan \\ ${ }^{5}$ Second Department of Internal Medicine, Faculty of Medical Science, University of Fukui Hospital, Yoshida-gun, Fukui, Japan \\ ${ }^{6}$ Department of Clinical Laboratory, Saiseikai Kumamoto Hospital, Kumamoto-city, Kumamoto, Japan \\ ${ }^{7}$ Department of Radiological Technology, Faculty of Medical Technology, Niigata University of Health and Welfare, Niigata-city, Niigata, Japan \\ ${ }^{8}$ Department of Visiting Nurse Himawari Station, Fukui Kouseikai-Group, Fukui-city, Fukui, Japan \\ ${ }^{9}$ Department of Radiology, University of Fukui Hospital, University of Fukui Hospital, Yoshida-gun, Fukui, Japan \\ ${ }^{10}$ Department of Neurosurgery, Aso Medical Center, Aso-City, Kumamoto, Japan \\ ${ }^{11}$ Department of Neurology, Kumamoto City Hospital, Kumamoto-city, Kumamoto, Japan \\ ${ }^{12}$ Second Department of Internal Medicine, Faculty of Medical Science, University of Fukui Hospital, Yoshida-gun, Fukui, Japan \\ ${ }^{13}$ Department of Cardiology, Toyama Red Cross Hospital, Toyama-city, Toyama, Japan \\ ${ }^{14}$ Department of Community Medicine, Faculty of Medical Science, University of Fukui, Yoshida-gun, Fukui, Japan
}

\begin{abstract}
Background: We aimed to investigate and report the relationship between hypertension treatment status and cardiac functions among temporary housing residents after the Kumamoto earthquake.

Material and methods: Ultrasonic cardiography examinations were conducted for 56 residents at temporary housing complexes in Minami Aso village in Kumamoto Prefecture in December 2016. The subjects were divided into the following three groups according to the incidence of hypertension and the antihypertensive treatment status: normal (without hypertension), treated, and untreated. Subsequently, their cardiac functions were compared.

Results: Age and BMI were found to be positive predictors for hypertension. Moreover, age, LAVI, and LVMI tended to be higher in the untreated group than in the treated group. Moderate or severe mitral regurgitation was significantly more common in the untreated group than in the treated group.

Conclusions: Controlling blood pressure may help to prevent new cardiac diseases (e.g., valve regurgitation) among survivors after a major disaster. In addition, for survivors who are severely affected by psychological stress, improving the mental stress support system may be an effective measure to reduce health problems.
\end{abstract}

Key words: Kumamoto earthquakes; temporary housing; ultrasonic cardiography; hypertension

$$
\text { Arterial Hypertens. 2021, vol. 25, no. 2, pages: 69-76 }
$$

DOI: $10.5603 /$ AH.a2021.0010

Address for correspondence: Osamu Yamamura, Department of Community Medicine, Faculty of Medical Science, University of Fukui, Fukui, Japan; e-mail: kapi@u-fukui.ac.jp

This article is available in open access under Creative Common Attribution-Non-Commercial-No Derivatives 4.0 International (CC BY-NC-ND 4.0) license, allowing to download articles and share them with others as long as they credit the authors and the publisher, but without permission to change them in any way or use them commercially

V M Copyright (C 2021 Via Medica, ISSN 2449-6170, e-ISSN 2449-6162 


\section{Introduction}

Long-term blood pressure management is important immediately after a disaster $[1,2]$. In our previous study, we conducted medical examinations using ultrasonic cardiography (UCG) in the disaster area of the Great East Japan Earthquake and observed a yearly increase in the number of disaster victims based on clinical findings (primarily patients with mild diseases, such as heart valve disease) [3]. This increase in clinical findings was found to be associated with the elevation in blood pressure levels (pulse pressure) [3]. Moreover, an increase in the number of disaster-related diseases associated with the cessation of treatment was a concern among patients with chronic diseases after a major disaster [4]. The cessation of antihypertensive treatment was found to be increased among disaster victims with psychological distress in the disaster area of the Great East Japan Earthquake [5]. In the present study, we conducted a UCG screening to prevent disaster-related diseases among temporary housing residents in Minami Aso village, the area affected by the Kumamoto earthquake in 2016. This village is located in the northeastern part of Kumamoto Prefecture, which is rich in nature and is also an agricultural and forestry industry area, with a population of approximately 10,000. The Kumamoto earthquake resulted in 27 deaths (including disaster-related deaths) and 149 mild to severe injuries on people, and 1577 houses were also completely or partially destroyed. The maximum number of evacuees was approximately 3000. The number of households and evacuees in the temporary housing in Minami Aso village reached approximately 390 and 1000 , respectively. The situation in this village was different to that in other disaster areas in two aspects. First, as roads and railways were cut off due to the collapse of the Great Aso
Bridge (bridge length: $200 \mathrm{~m}$ ) as well as landslides, disaster victims became temporally isolated $[6,7]$. Second, regional healthcare support was reduced because the only emergency hospital in Minami Aso village (Aso Tateno Hospital) was damaged and temporarily closed [6,7]. To our knowledge, no previous studies have conducted a UCG screening targeting disaster victims in a rural area or investigated the relationship between hypertension treatment status and UCG findings, such as the left atrial volume index (LAVI), left ventricular mass index (LVMI), and left ventricular valve disease, and reported the impact on the heart. Therefore, in the present study, we conducted a UCG screening targeting disaster victims in the temporary housing in Minami Aso village. Our aim was to discuss the UCG findings and the prevalence of hypertension according to the antihypertensive treatment status.

\section{Material and methods}

\section{Subjects}

The UCG screening was performed in the temporary housing complexes in Minami Aso village in Kumamoto Prefecture over a period of 2 days, December 24 and 25, 2016 (Fig. 1). The subjects participated in the screening on a voluntary basis, when our medical examination program using UCG aimed at preventing disaster-related diseases was announced. The screening was performed on 60 subjects who were the residents of the temporary housing. Of these subjects, we excluded four individuals with atrial fibrillation, and the analysis was performed using the data of 56 subjects ( 10 men, 46 women; mean age $=71.0 \pm 13.8$ years). Subjects with hypertension were defined as those previously diagnosed with hypertension according to their response in the ques-

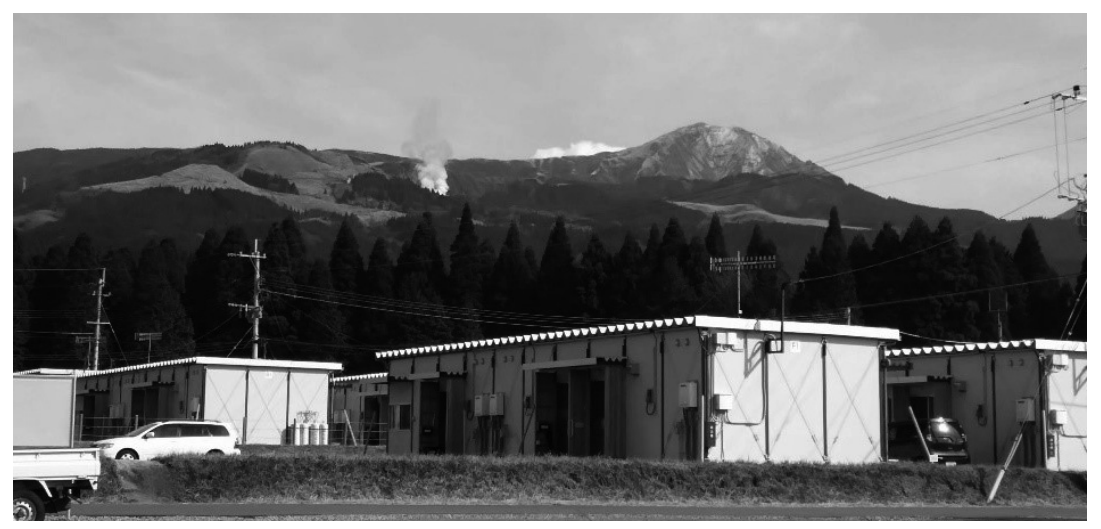

Figure 1. Temporary housing complexes in Minami Aso Village in Kumamoto Prefecture 
tionnaire. There were 29 subjects ( 4 men, 25 women; mean age $=76.0 \pm 7.9$ years) in the group with hypertension and 27 subjects ( 6 men, 21 women; mean age $=65.6 \pm 16.8$ years) in the normal group (without hypertension). Based on the antihypertensive treatment status, the subjects were also divided into three groups: normal, treated, and untreated. Among those with hypertension, there were 22 subjects ( 4 men, 18 women; mean age $=75.2 \pm 8.4$ years) in the treated group and seven subjects $(0$ men, 7 women; mean age $=78.5 \pm 5.7$ years) in the untreated group.

\section{Medical examination venue and organization of examinations}

Examinations were conducted at a meeting place in the temporary housing complexes in Minami Aso village in Kumamoto Prefecture. The medical examination team was organized primarily by University of Fukui, with cooperation from volunteer doctors, nurses, medical radiology technologists, laboratory medical technologists, medical students, and dental students in the Hokuriku region.

\section{Medical examination parameters and methods}

Our UCG screening activity was performed in temporary housing in cooperation with the local authority of Minami Aso village. Posters to raise awareness about disaster-related diseases prevention were displayed one month prior to the screening. Participation in the screening was on a voluntary basis. After obtaining written consent from all subjects, medical examinations were conducted in the following order: a medical questionnaire, blood pressure measurement (measured only once), UCG, and explanation of the results [3]. All subjects were asked to complete a questionnaire to collect information on their age, sex, height, weight, medical history (diabetes, hypertension, heart disease, and dyslipidemia), and lifestyle (daily exercise, smoking, and drinking: yes/no) [3]. The underlying diseases (dyslipidemia, diabetes mellitus, heart disease, hypertension) of the subjects were reported based on their answers to the self-report questionnaire. Body mass index (BMI), which is a measure of body fat based on height and weight, was calculated, and the body surface area (BSA) was also calculated to make comparisons among individuals with different body shapes. Subjects were first divided into groups depending on whether they had hypertension or not and further divided into the following three groups: normal (without hypertension), treated, and untreated. Screening was performed using portable devices due to the space limitation $[3,8]$. The assessment was conducted based on the guidelines of the American Society of Echocardiography and the European Association of Cardiovascular Imaging, as well as the Japanese Normal Values for Echocardiographic Measurements Project study as criteria for Japanese people [9-11]. The left atrial (LA) volume was measured using the area-length method (the length was measured in both the 4- and 2-chamber views and the shortest of these two length measurements was used in the formula), and the LAVI was calculated by dividing the LA volume by the BSA [9-11]. The left ventricular end-diastolic dimension, left ventricular end-systolic dimension, interventricular septal thickness, and left ventricular posterior wall thickness were measured using the B-mode method. The LV mass was calculated using the following formula:

$$
\begin{gathered}
\text { LV mass }(g)=1.05[(\text { LVIDd }+ \text { IVSTd }+ \text { PWTd (3) } \\
- \text { LVIDd })(3)] .
\end{gathered}
$$

The LVMI (grams per square meter $\left[\mathrm{g} / \mathrm{m}^{2}\right]$ ) was calculated by dividing the LV mass by the BSA to take body shapes into consideration [9-11]. Regarding mitral regurgitation (MR) and aortic regurgitation (AR), moderate or severe cases were defined as positive. The UCG screening was performed by ultrasonographers who had more than 5 years of experience and were certified by the Japan Society of Ultrasonics in Medicine. Before the screening session, a meeting was held to discuss the judging criteria to ensure uniformity [3]. Screening was performed using two portable devices with a Vivid iq (GE Healthcare, frequency range of $1.5-4.0 \mathrm{MHz}$ sector probe).

\section{Statistical analysis}

Age, systolic blood pressure, diastolic blood pressure, LAVI, and LVMI are reported as the mean \pm standard deviation, and nominal variables are reported as frequencies and percentages (\%). Statistical analysis was performed using EZR Ver. 1.28. The two study groups were compared using the Mann-Whitney $\mathrm{U}$ test and $\chi^{2}$ test (including Yates' continuity correction), and the three groups were compared using Fisher's exact test (multiple comparisons between the two groups: Bonferroni test) as well as the Kruskal-Wallis test (multiple comparisons between the two groups: Steel-Dwass post-hoc test). Multiple logistic regression analysis (stepwise method) was performed to identify positive predictors. A $\mathrm{p}$ value of $<0.05$ was defined as statistically significant. The Research Ethics Committee of University of Fukui approved the study (protocol number: 20160089; November 29, 2016). 


\section{Data availability}

The data associated with the paper are not publicly available but are available from the corresponding author on reasonable request.

\section{Results}

Subjects with or without hypertension and comparison of risk factors (Tab. 1)

Age $(65.6 \pm 16.8$ vs. $76.0 \pm 7.9$ years, $\mathrm{p}=0.0041)$ and BMI $\left(22.3 \pm 3.4\right.$ vs. $\left.25.2 \pm 4.9 \mathrm{~kg} / \mathrm{m}^{2}, \mathrm{p}=0.024\right)$ were significantly higher in the group with hypertension than in the group without hypertension. Multivariate analysis revealed that age [odds ratio: 1.110; 95\% confidence interval (CI): 1.020-1.190; $\mathrm{p}=0.0110]$ and BMI (odds ratio: 1.220; 95\% CI: $1.040-1.430 ; \mathrm{p}=0.0127$ ) were positive predictors of hypertension.

Subjects with or without hypertension and comparison of cardiac functions (Tab. 2).

The LAVI $(27.7 \pm 11.4$ vs. $36.0 \pm 14.9$, $\mathrm{p}=0.01742)$ and LVMI $(75.1 \pm 20.6$ vs. $90.9 \pm 29.3$, $\mathrm{p}=0.0126)$ were significantly higher in the group with hypertension than in the group without hypertension.

Subjects with treated or untreated hypertension and comparison of risk factors (Tab. 3).

Multiple comparisons were performed between the two groups after comparing the three groups.
The comparison of the three groups revealed a statistically significant difference with respect to age $(\mathrm{p}=0.035)$. The multiple comparisons conducted between the two groups revealed that age tended to be higher in the untreated group with hypertension than in the group without hypertension $(78.5 \pm 5.7$ vs. $65.6 \pm 16.8$ years, $\mathrm{p}=0.075$ ).

Subjects with treated or untreated hypertension and comparison of cardiac functions (Tab. 3).

Multiple comparisons were performed between the two groups after comparing the three groups. The comparison of the three groups revealed statistically significant differences with respect to the LAVI $(\mathrm{p}=0.033)$, the LVMI $(\mathrm{p}=0.026)$, and moderate or severe MR ( $p=0.008)$. The multiple comparisons performed between the two groups demonstrated that both the LAVI $(40.7 \pm 13.9$ vs. $27.7 \pm 11.4, \mathrm{p}=0.055)$ and the LVMI $(100.3 \pm 29.3$ vs. $75.1 \pm 20.6, \mathrm{p}=0.065)$ tended to be higher in the untreated group with hypertension than in the group without hypertension, and moderate or severe MR was significantly more common in the untreated group than in the treated group $(57.1 \%$ vs. $4.5 \%$, $\mathrm{p}=0.02)$.

\section{Discussion}

We conducted this study on subjects who were the temporary housing residents in Minami Aso village,

Table 1. Comparison of presence or absence of hypertension and background factors

\begin{tabular}{|c|c|c|c|c|c|c|}
\hline & $\begin{array}{l}\text { Non-hypertension group } \\
\begin{array}{c}\text { (N Group) } \\
\mathrm{n}=27\end{array}\end{array}$ & $\begin{array}{c}\text { Hypertension group } \\
\text { (T Group + U Group) } \\
\text { n }=29\end{array}$ & $p$ value & $\begin{array}{l}\text { Odds } \\
\text { ratio }\end{array}$ & $\begin{array}{c}95 \% \mathrm{Cl} \\
\text { Lower-upper }\end{array}$ & $\mathrm{p}$ value \\
\hline & \multicolumn{3}{|c|}{ Univariate analysis } & \multicolumn{3}{|c|}{ Multivariate analysis } \\
\hline Age (years) & $65.6 \pm 16.8$ & $76.0 \pm 7.9$ & 0.0041 & 1.11 & $1.020-1.190$ & 0.011 \\
\hline Gender (male/female) & $6 / 21$ & $4 / 25$ & 0.636 & 0.159 & $0.024-1.030$ & 0.053 \\
\hline \multicolumn{7}{|l|}{ Blood pressure } \\
\hline SBP [mm Hg] & $134.8 \pm 18.4$ & $138.4 \pm 15.3$ & 0.43 & - & - & - \\
\hline $\mathrm{DBP}[\mathrm{mm} \mathrm{Hg}]$ & $78.9 \pm 10.3$ & $81.4 \pm 9.2$ & 0.347 & - & - & - \\
\hline $\mathrm{BMI}$ & $22.3 \pm 3.4$ & $25.2 \pm 4.9$ & 0.024 & 1.22 & $1.040-1.430$ & 0.012 \\
\hline \multicolumn{7}{|l|}{ Lifestyle } \\
\hline Exercises, n (\%) & $12(44.4)$ & $18(62.1)$ & 0.164 & 0.707 & $0.172-2.910$ & 0.632 \\
\hline Smoker, n (\%) & $2(7.4)$ & $0(0)$ & 0.614 & - & - & - \\
\hline Drinking, $n(\%)$ & $7(25.9)$ & $4(13.8)$ & 0.233 & 0.561 & $0.0853-3.690$ & 0.547 \\
\hline \multicolumn{7}{|l|}{ Underlying disease } \\
\hline $\mathrm{DM}, \mathrm{n}(\%)$ & $2(7.4)$ & $3(13.6)$ & 1 & 1.43 & $0.139-14.700$ & 0.764 \\
\hline Heart disease, $n(\%)$ & $3(11.1)$ & $4(18.2)$ & 1 & 0.636 & $0.0924-4.380$ & 0.646 \\
\hline $\mathrm{DL}, \mathrm{n}(\%)$ & $4(14.8)$ & $8(27.6)$ & 0.402 & 1.41 & $0.296-6.720$ & 0.665 \\
\hline
\end{tabular}

Mean \pm standard deviation. Number of cases (\%); Nominal variables: 2 test (between each pair of two groups); Continuous variables: Mann-Whitney $\mathrm{U}$ test (between each pair of two groups); SBP — systolic blood pressure; DBP — diastolic blood pressure; BMI — body mass index; DM — diabetes mellitus; DL—dyslipidemia 
Table 2. Comparison of ultrasonographic findings according to presence or absence of hypertension

\begin{tabular}{|l|c|c|c|}
\hline & $\begin{array}{c}\text { Non-hypertension group } \\
\text { (N Group) } \\
\mathbf{n}=\mathbf{2 7}\end{array}$ & $\begin{array}{c}\text { Hypertension group } \\
\text { (T Group + U Group) } \\
\mathbf{n}=\mathbf{2 9}\end{array}$ & p value \\
\hline LAVI & $27.7 \pm 11.4$ & $36.0 \pm 14.9$ & 0.01742 \\
\hline LVMI & $75.1 \pm 20.6$ & $90.9 \pm 29.3$ & 0.0126 \\
\hline MR over moderate, $\mathrm{n}(\%)$ & $4(14.8)$ & $5(17.2)$ & 1.000 \\
\hline AR over moderate, $\mathrm{n}(\%)$ & $4(8.3)$ & $3(10.3)$ & 0.919 \\
\hline
\end{tabular}

Mean \pm standard deviation. Number of cases (\%); Nominal variables: ${ }^{2}$ test (between each pair of two groups); Continuous variables: Mann-Whitney $\mathrm{U}$ test (between each pair of two groups); LAVI — LA volume index, LVMI — left ventricular mass index; MR — mitral regurgitation; AR — aortic regurgitation

Table 3. Subjects with treated or untreated hypertension and comparison of cardiac functions and risk factors

\begin{tabular}{|c|c|c|c|c|}
\hline & $\begin{array}{l}\text { Non-hypertension group } \\
\begin{array}{c}\text { (N Group) } \\
\mathrm{n}=27\end{array}\end{array}$ & $\begin{array}{l}\text { Hypertension group } \\
\begin{array}{c}\text { (T Group) } \\
\mathbf{n}=22\end{array}\end{array}$ & $\begin{array}{l}\text { HT Untreated group } \\
\begin{array}{c}\text { (U Group) } \\
\mathbf{n}=\mathbf{7}\end{array}\end{array}$ & p value \\
\hline Age (years) & $65.6 \pm 16.8$ & $75.2 \pm 8.4$ & $78.5 \pm 5.7$ & $0.035^{\mathrm{a}}$ \\
\hline Gender (male/female) & $6 / 21$ & $4 / 18$ & $0 / 7$ & 0.554 \\
\hline \multicolumn{5}{|l|}{ Blood pressure } \\
\hline SBP [mm Hg] & $134.8 \pm 18.4$ & $141.4 \pm 14.5$ & $129.2 \pm 15.2$ & 0.115 \\
\hline $\mathrm{DBP}[\mathrm{mm} \mathrm{Hg}]$ & $78.9 \pm 10.3$ & $82.8 \pm 9.4$ & $77.0 \pm 7.7$ & 0.201 \\
\hline BMI & $22.3 \pm 3.4$ & $25.9 \pm 5.3$ & $23.1 \pm 2.3$ & 0.059 \\
\hline \multicolumn{5}{|l|}{ Lifestyle } \\
\hline Exercises, n (\%) & $12(44.4)$ & $12(54.5)$ & $6(85.7)$ & 0.164 \\
\hline Smoker, n (\%) & $2(7.4)$ & $0(0)$ & $0(0)$ & 0.614 \\
\hline Drinking, $\mathrm{n}(\%)$ & $7(25.9)$ & $2(9.1)$ & $2(28.6)$ & 0.233 \\
\hline \multicolumn{5}{|l|}{ Underlying disease } \\
\hline $\mathrm{DM}, \mathrm{n}(\%)$ & $2(7.4)$ & $3(13.6)$ & $0(0)$ & 0.675 \\
\hline Heart disease, $\mathrm{n}(\%)$ & $3(11.1)$ & $4(18.2)$ & $0(0)$ & 0.625 \\
\hline $\mathrm{DL}, \mathrm{n}(\%)$ & $4(14.8)$ & $5(22.7)$ & $3(42.9)$ & 0.255 \\
\hline \multicolumn{5}{|l|}{ Ultrasonographic findings } \\
\hline LAVI & $27.7 \pm 11.4$ & $34.5 \pm 15.2$ & $40.7 \pm 13.9$ & $0.033^{b}$ \\
\hline LVMI & $75.1 \pm 20.6$ & $88.0 \pm 29.4$ & $100.3 \pm 29.3$ & $0.026^{c}$ \\
\hline MR over moderate, $\mathrm{n}(\%)$ & $4(14.8)$ & $1(4.5)$ & $4(57.1)$ & $0.008^{d}$ \\
\hline AR over moderate, n (\%) & $4(8.3)$ & $2(9.1)$ & $1(14.3)$ & 0.864 \\
\hline
\end{tabular}

Mean \pm standard deviation. Number of cases (\%). Nominal variables: Fisher test ( $\mathrm{p}$ value adjustment method: Bonferroni); Continuous variables: Kruskal-Wallis test (p value adjustment method: steel-Dwass); a:p value adjustment method: steel-Dwass; N Group vs. T Group $p=0.156 ; \mathrm{N}$ Group vs. U Group $p=0.075 ; \mathrm{T}$ Group vs. U Group $p=0.423 ;$ b; value adjustment method: steel-Dwass; $N$ Group vs. T Group $p=0.156 ; N$ Group vs. $U$ Group $p=0.055$, T Group vs. $U$ Group $p=0.532 ;$ c:p value adjustment method: Bonferroni; $N$ Group vs. T Group $p=0.109, N$ Group vs. U Group $p=0.065$, T Group vs. U Group $p=0.485 ;$ d p value adjustment method: Bonferroni; N Group vs. T Group $p=1.00, N$ Group vs. U Group $p=0.11$, T Group vs. U Group $\mathrm{p}=0.02 ; \mathrm{SBP}$ - systolic blood pressure; DBP — diastolic blood pressure; BMI — body mass index; DM — diabetes mellitus; DL — dyslipidemia; HT — hypertension

the area affected by the Kumamoto earthquake in 2016. We divided these subjects into two groups (with or without hypertension) and compared their risk factors and UCG findings. We then divided them into three groups, viz., normal (without hypertension), treated, and untreated. The multiple comparisons conducted between the two groups demonstrated that age, BMI, LAVI, and LVMI were significantly higher in the group with hypertension than in the group without hypertension, and the risk factors for hypertension were age and BMI. Our re- sults of the multiple comparisons performed according to the hypertension treatment status also showed that moderate or severe MR was significantly more common in the untreated group than in the treated group.

Obesity, age, and alcohol consumption have been identified as risk factors for hypertension in a previous follow-up study of non-hypertensive people in Japan [12]. Our present study also found that age and BMI were the risk factors for hypertension. After the Great East Japan Earthquake, the risk of obesity 
in elderly individuals was suggested to have increased due to moving houses and dietary changes [13]. Elderly individuals and people with obesity have been reported as at-risk populations in a post-disaster setting. Therefore, we assumed that obesity and age were also associated with the development of hypertension among disaster victims in the temporary housing after the Kumamoto earthquake.

Left ventricular hypertrophy (LVH) occurs as a consequence of the compensatory mechanism in response to the left ventricular pressure overload and has been characterized to be associated with hypertension [14]. Moreover, LA load increases due to stiffness in the left ventricle as well as declined left ventricular diastolic function associated with hypertension [15]. Our study also showed that both the LAVI and the LVMI were significantly higher in the group with hypertension. Although our study population contained several elderly people, the UCG findings allowed us to presume the influence of hypertension. Hypertension may also lead to the development of cardiovascular diseases and atrial fibrillation $[14,15]$. The results of our study suggest that blood pressure management under difficult living environments in a post-disaster setting is necessary and important for the prevention of further heart diseases over a long-term period [1].

We also identified characteristic findings in our study. In the multiple comparisons conducted between the two groups according to the hypertension treatment status, we found that LVMI had a tendency to be higher in the untreated group with hypertension than in the group without hypertension. Given the relationship between hypertension and LVMI, the risk of LVH can be reduced by hypertension treatment [16]. LAVI also had a tendency to be higher in the untreated group, and this would reflect an increase in the left ventricular hemodynamic load. As studies have reported the effect of preload and afterload on MR [17, 18], we assumed that, owing to the heavier ventricular hemodynamic load, more subjects in the untreated group had moderate or severe MR compared to those in the treated group. As we found no subject with a heart disease in the untreated group, MR may have occurred after the disaster.

Psychological distress has been reported among disaster victims who discontinued their hypertension treatment after the Great East Japan Earthquake [5]. In addition, more severe cases of psychological distress have been reported among elderly individuals and women in particular in the post-disaster setting $[19,20]$. In our study, the subjects in the untreated group consisted of only elderly women. Long-term mental support for elderly women after the disaster may help encourage them to undergo chronic disease treatment or prevent the cessation of treatment. According to the health survey associated with the Kumamoto earthquake, the reasons for being untreated or discontinuing their treatment were "hardly having enough time," followed by "too far to visit the regular primary care physician." In our study target area, that is, Minami Aso village, public roads and the only emergency hospital in the village were temporarily closed because of the earthquake. In such a particular situation, we can estimate that there will be a certain number of people who do not initiate treatment or discontinue treatment. Therefore, it is important to establish a long-term healthcare support system.

An important aspect of this study is that it evaluated the survivors who were more susceptible to developing post-traumatic stress disorder (PTSD) after the natural disaster. Disaster-related diseases are highly associated with stress, and among these, hypertension-related diseases (stroke, myocardial infarction, aortic dissection, and heart failure) can occur immediately after a disaster and persist for several months [1]. After the Great Hanshin-Awaji Earthquake, the number of deaths from coronary heart disease and stroke increased by 1.5 and 1.9 times, respectively $[1,21,22]$. In the case of the Great East Japan Earthquake, heart failure, acute coronary syndrome, stroke, and cardiovascular disease (CVD) increased significantly after the earthquake compared with the previous three years [23]. On the other hand, the incidence rate of post-disaster PTSD has been reported to be $5-10 \%$ for the general inhabitants and $10-20 \%$ for rescuers [24]. Moreover, the prevalence of PTSD among cardiovascular patients after the Great East Japan Earthquake was 14.7\%, and it was as high as $36.3 \%$ in the area affected by the tsunami alone [25]. PTSD was frequently observed among CVD patients in the post-earthquake setting, suggesting that it had a significant impact on their prognosis [26]. It has also been suggested that trauma exposure and PTSD symptoms are associated with an increased risk of developing CVD [27The novel coronavirus disease (COVID-19) is currently spreading throughout the world. In survivors of suspected or confirmed COVID-19 cases, an association with PTSD has been reported, similar to the cases for survivors of natural disasters [28, 29]. A meta-analysis of post-traumatic stress and psychological stress symptoms in the general population during COVID-19 showed that the prevalence of post-traumatic stress and psychological stress was $23.8 \%$ and $24.8 \%$, respectively [28]. It was also reported that the severity of COVID-19 symptoms 
was associated with an increase in PTSD symptoms [29]. Given these reports, it is important to take effective measures to reduce the adverse health effects associated with hypertension-related diseases in situations that are greatly influenced by mental stress, not only by controlling blood pressure but also by improving the mental stress support system.

This study has several limitations. First, because the screening was conducted by a volunteer-based team within a limited timeframe, not all the disaster victims in temporary housing were targeted. Therefore, we could not exclude the possibility that the sample was not representative of the disaster victims. Second, it is possible that the sample was biased toward the health-conscious group. Third, the blood pressure level in the untreated group was low, although not statistically significant, implying the possibility that the blood pressure measurement (measured only once) was inaccurate. Fourth, as the medical history and lifestyle were judged by a self-reported questionnaire, considerations based on the actual influence were not made. Finally, as we did not have the UCG data before the disaster for the regional residents, a pre-post comparison was not conducted. Therefore, future studies taking these five limitations into consideration are necessary.

\section{Conclusions}

Controlling blood pressure may help to prevent new cardiac diseases (e.g., valve regurgitation) among survivors after a major disaster. In addition, for survivors who are severely affected by psychological stress, improving the mental stress support system may be an effective measure to reduce health problems.

\section{Author contributions}

H.O., O.Y, and H.Te. designed the study, collected data, and contributed to manuscript writing. H.Tsu., T.Hi, S.E., T.Y., S.D., Y.M, T.K., Y.K., Y.H., T.Ha., and B.K. also collected data and contributed to manuscript writing. H.Tsu. performed statistical analysis, collected data, and contributed to manuscript writing.

\section{Acknowledgments}

This study was conducted in cooperation with the medical staff (doctor, nurse, public health nurse, radiological technologist, and clinical laboratory technologist), office workers, and students of Minamiaso Village Office, Kagosima, Kamamoto, Ishikawa, Toyama, and Fukui. We would like to express our gratitude to them.

\section{Conflicts of interest}

The authors certify that there is no conflict of interest with any financial organization regarding the material discussed in the manuscript.

\section{Funding}

The authors report no involvement in the research by the sponsor that could have influenced the outcome of this work.

\section{Trial registration}

Investigation and research on disaster-related diseases in the Kumamoto earthquake (Aso District) https://upload.umin.ac.jp/cgi-open-bin/ctr_e/ctr_ view.cgi? recptno=R000044934.UMIN000039410. R000044934.6 February 2020.

\section{References}

1. Kario K. Disaster hypertension — its characteristics, mechanism, and management. Circ J. 2012; 76(3): 553-562, doi: 10.1253/ circj.cj-11-1510, indexed in Pubmed: 22327030.

2. Nishizawa M, Hoshide S, Okawara Y, et al. Strict Blood Pressure Control Achieved Using an ICT-Based Home Blood Pressure Monitoring System in a Catastrophically Damaged Area After a Disaster. J Clin Hypertens (Greenwich). 2017; 19(1): 26-29, doi: 10.1111/jch.12864, indexed in Pubmed: 27400261.

3. Onishi H, Yamamura O, Ueda S, et al. Ultrasound cardiography examinations detect victims' long-term realized and potential consequences after major disasters: a case-control study. Environ Health Prev Med. 2018; 23(1): 37, doi: 10.1186/s12199-0180721-4, indexed in Pubmed: 30103685.

4. JCS, JSH and JCC Joint Working Group. Guidelines for Disaster Medicine for Patients With Cardiovascular Diseases (JCS 2014/JSH 2014/JCC 2014) — Digest Version . Circ J. 2016; 80(1): 261-284, doi: 10.1253/circj.CJ-66-0121, indexed in Pubmed: 26632533.

5. Nakaya N, Nakamura T, Tsuchiya N, et al. Psychological Distress and the Risk of Withdrawing From Hypertension Treatment After an Earthquake Disaster. Disaster Med Public Health Prep. 2017; 11(2): 179-182, doi: 10.1017/dmp.2016.102, indexed in Pubmed: 28430096.

6. Goda K, Campbell G, Hulme L, et al. The 2016 Kumamoto Earthquakes: Cascading Geological Hazards and Compounding Risks. Front Built Environ. 2016; 2, doi: 10.3389/ fbuil.2016.00019.

7. Shinichi U. About the role played by Aso Tateno Hospital. Aso community medicine plan Coordination Meeting (in Japanese). https://www.pref.kumamoto.jp/common/UploadFileOutput.ashx?c_id=3\&id=26950\&sub_id=1\&flid=183278. Accessed October 1 2019; March 72019 . (in Japanese) (October 1, 2019).

8. Ohyama R, Murata K, Tanaka N, et al. [Accuracy and usefulness of ultraportable hand-carried echocardiography system]. J Cardiol. 2001; 37(5): 257-262, indexed in Pubmed: 11392894.

9. Nagueh SF, Smiseth OA, Appleton CP, et al. Houston, Texas; Oslo, Norway; Phoenix, Arizona; Nashville, Tennessee; Hamilton, Ontario, Canada; Uppsala, Sweden; Ghent and Liège, Belgium; Cleveland, Ohio; Novara, Italy; Rochester, Minnesota; Bucharest, Romania; and St. Louis, Missouri. Recommendations for the Evaluation of Left Ventricular Diastolic Function by Echocardiography: An Update from the American Society of Echocardiography and the European Association of Cardiovascular Imaging. J Am Soc Echocardiogr. 2016; 29(4): 277-314, doi: 10.1016/j. echo.2016.01.011, indexed in Pubmed: 27037982. 
10. Lang RM, Badano LP, Mor-Avi V, et al. Recommendations for cardiac chamber quantification by echocardiography in adults: an update from the American Society of Echocardiography and the European Association of Cardiovascular Imaging. J Am Soc Echocardiogr. 2015; 28(1): 1-39.e14, doi: 10.1016/j. echo.2014.10.003, indexed in Pubmed: 25559473.

11. Daimon M, Watanabe $H$, Abe Y, et al. JAMP Study Investigators. Normal values of echocardiographic parameters in relation to age in a healthy Japanese population: the JAMP study. Circ J. 2008; 72(11): 1859-1866, doi: 10.1253/circj.cj-08-0171, indexed in Pubmed: 18827372

12. Arima H, Kiyohara Y, Kato I, et al. Alcohol reduces insulin-hypertension relationship in a general population The Hisayama study. J Clin Epidemiol. 2002; 55(9): 863-869, doi: 10.1016/ s0895-4356(02)00441-9, indexed in Pubmed: 12393073.

13. Hikichi H, Aida J, Kondo K, et al. Residential relocation and obesity after a natural disaster: A natural experiment from the 2011 Japan Earthquake and Tsunami. Sci Rep. 2019; 9(1): 374, doi: 10.1038/ s41598-018-36906-y, indexed in Pubmed: 30675013.

14. Levy D, Garrison RJ, Savage DD, et al. Left ventricular mass and incidence of coronary heart disease in an elderly cohort. The Framingham Heart Study. Ann Intern Med. 1989; 110(2): 101-107, doi: 10.7326/0003-4819-110-2-101, indexed in Pubmed: 2521199.

15. Vaziri SM, Larson MG, Lauer MS, et al. Influence of blood pressure on left atrial size. The Framingham Heart Study. Hypertension. 1995; 25(6): 1155-1160, doi: 10.1161/01.hyp.25.6.1155, indexed in Pubmed: 7768556.

16. Liebson PR, Grandits GA, Dianzumba S, et al. Comparison of five antihypertensive monotherapies and placebo for change in left ventricular mass in patients receiving nutritional-hygienic therapy in the Treatment of Mild Hypertension Study (TOMHS). Circulation. 1995; 91(3): 698-706, doi: 10.1161/01.cir.91.3.698, indexed in Pubmed: 7828296.

17. Greenberg BH, Massie BM, Brundage BH, et al. Beneficial effects of hydralazine in severe mitral regurgitation. Circulation. 1978; 58(2): 273-279, doi: 10.1161/01.cir.58.2.273, indexed in Pubmed: 668075.

18. Chatterjee K, Parmley WW, Swan HJ, et al. Beneficial effects of vasodilator agents in severe mitral regurgitation due to dysfunction of subvalvar apparatus. Circulation. 1973; 48(4): 684-690, doi: 10.1161/01.cir.48.4.684, indexed in Pubmed: 4744778.

19. Jia Z, Tian W, Liu W, et al. Are the elderly more vulnerable to psychological impact of natural disaster? A population-based survey of adult survivors of the 2008 Sichuan earthquake. BMC Public Health. 2010; 10: 172, doi: 10.1186/1471-2458-10-172, indexed in Pubmed: 20353554.
20. Kuwabara H, Shioiri T, Toyabe SI, et al. Factors impacting on psychological distress and recovery after the 2004 NiigataChuetsu earthquake, Japan: community-based study. Psychiatry Clin Neurosci. 2008; 62(5): 503-507, doi: 10.1111/j.14401819.2008.01842.x, indexed in Pubmed: 18950368.

21. Kario K, Ohashi T. Increased coronary heart disease mortality after the Hanshin-Awaji earthquake among the older community on Awaji Island. Tsuna Medical Association. J Am Geriatr Soc. 1997; 45(5): 610-613, doi: 10.1111/j.1532-5415.1997. tb03096.x, indexed in Pubmed: 9158584.

22. Kario K, Ohashi T. After a major earthquake, stroke death occurs more frequently than coronary heart disease death in very old subjects. J Am Geriatr Soc. 1998; 46(4): 537-538, doi: 10.1111/ j.1532-5415.1998.tb02485.x, indexed in Pubmed: 9560086.

23. Aoki T, Takahashi J, Fukumoto Y, et al. The Great East Japan Earthquake Disaster and cardiovascular diseases. Eur Heart J. 2012; 33(22): 2796-2803, doi: 10.1093/eurheartj/ehs288, indexed in Pubmed: 22930461.

24. Neria Y, Nandi A, Galea S. Post-traumatic stress disorder following disasters: a systematic review. Psychol Med. 2008; 38(4): 467-480, doi: 10.1017/S0033291707001353, indexed in Pubmed: 17803838.

25. Onose T, Nochioka K, Sakata Y, et al. CHART-2 Investigators. Predictors and prognostic impact of post-traumatic stress disorder after the great East Japan earthquake in patients with cardiovascular disease. Circ J. 2015; 79(3): 664-667, doi: 10.1253/circj. CJ-14-1403, indexed in Pubmed: 25746552.

26. Shiozaki M, Iso H, Ohira T, et al. Longitudinal risk of cardiovascular events in relation to depression symptoms after discharge among survivors of myocardial infarction. Osaka Acute Coronary Insufficiency Study. Circ J. 2011; 75(12): 2878-2884, doi: 10.1253/circj.cj-10-1304, indexed in Pubmed: 21937836.

27. Sumner JA, Kubzansky LD, Elkind MSV, et al. Trauma Exposure and Posttraumatic Stress Disorder Symptoms Predict Onset of Cardiovascular Events in Women. Circulation. 2015; 132(4): 251-259, doi: 10.1161/CIRCULATIONAHA.114.014492, indexed in Pubmed: 26124186.

28. Cooke JE, Eirich R, Racine N, et al. Prevalence of posttraumatic and general psychological stress during COVID-19: A rapid review and meta-analysis. Psychiatry Res. 2020; 292: 113347, doi: 10.1016/j.psychres.2020.113347, indexed in Pubmed: 32763477.

29. Chamberlain SR, Grant JE, Trender W, et al. Post-traumatic stress disorder symptoms in COVID-19 survivors: online population survey. BJPsych Open. 2021; 7(2): e47, doi: 10.1192/bjo.2021.3, indexed in Pubmed: 33557964. 